\title{
A busca da graduação em enfermagem como opção dos técnicos e auxiliares de enfermagem*
}

\author{
UNDERGRATUATE NURSING EDUCATION AS AN OPTION FOR NURSING \\ TECHNICIANS AND ASSISTANTS
}

\section{LA BÚSQUEDA DEL PRE GRADO EN ENFERMERÍA COMO OPCIÓN DE LOS TÉCNICOS Y AUXILIARES DE ENFERMERÍA}

\section{Neuma Vital Julca Medina', Regina Toshie Takahashi ${ }^{2}$}

\section{RESUMO}

Este estudo teve como objetivo apreender os motivos que levam técnicos e auxiliares de enfermagem a buscarem a graduação nesta profissão. Realizado em um hospital escola, na cidade de São Paulo, sob a perspectiva da pesquisa qualitativa e como metodologia, a História Oral Temática e a Análise Categorial Temática. Deste trabalho participaram onze colaboradores: três técnicas de enfermagem e oito auxiliares de enfermagem.

\section{PALAVRAS-CHAVE}

Estudantes de enfermagem. Motivação.

Auxiliares de enfermagem.

\begin{abstract}
The aim of this study was to understand the reasons that lead both nursing technicians and assistants to enter undergraduate nursing programs. This study was carried out in a teaching hospital in the city of Sao Paulo, under a qualitative research perspective, and the methodologies adopted were the Thematic Oral History and the Thematic Categorical Analysis. There were eleven participants: three nursing technicians and eight nursing assistants.
\end{abstract}

\section{KEYWORDS}

Students, nursing.

Motivation.

Nurses' aides.

\section{RESUMEN}

Este estudio tuvo como objetivo, conocer los motivos que influenciaron al técnico $y$ auxiliar de enfermería a graduarse, a nivel superior, en su misma profesión. Fue realizado en un hospital docente de la ciudad de San Pablo, bajo la perspectiva de la investigación cualitativa y como metodología, la historia oral temática y el análisis de categoría temática. Paticiparon once colaboradores, siendo tres técnicos de enfermería y ocho auxiliares de enfermería.

\section{PALABRAS CLAVE}

Estudiantes de enfermería. Motivación. Auxiliares de enfermería.

\footnotetext{
* Extraído da Dissertação de Mestrado "A busca da Graduação em enfermagem como opção dos técnicos e auxiliares de enfermagem", Escola de Enfermagem da USP (EEUSP), 2002.

1 Enfermeira assistencial da Unidade de Terapia Intensiva Adulto do Hospital Universitário da USP. Mestre em Administração em Serviços de

Enfermagem pela EEUSP.

neumavjm@mail.hu.usp.br 2 Enfermeira. Doutora em Educação. Professora do Departamento de Orientação Profissional da EEUSP. Orientadora.
} 


\section{INTRODUÇÃO}

Nos últimos anos, técnicos e auxiliares de enfermagem têm procurado a graduação em Enfermagem.

Para Zanei ${ }^{(1)}$, dos diversos motivos que levam os trabalhadores em enfermagem a optar pela graduação, destacam-se os seguintes: é um curso menos seletivo, permite a ascensão profissional, melhora o conhecimento científico e, conseqüentemente, possibilita mudar de status dentro da equipe.

Hoje, as faculdades privadas de enfermagem têm atraído cada vez mais o profissional de enfermagem de nível médio, oferecendo bolsas de estudo e, inclusive, abrindo unidades na periferia das grandes cidades, com o intuito de facilitar o acesso deste estudante à faculdade.

Segundo Zanei ${ }^{(2)}$ o profissional de nível médio de enfermagem ao buscar a "elevação de grau dentro da mesma profissão mostra-se como uma questão curiosa e ao mesmo tempo inquietante", pois a escolha não visa apenas melhores salários, já que os rendimentos dos profissionais desta área são pouco promissores quando comparados com outras profissões. Além disso, estudar e trabalhar para arcar com o custo elevado da mensalidade é uma tarefa desgastante que resulta em baixa produtividade, tanto nos estudos quanto no trabalho. Estes alunos enfrentam, ainda, a falta de tempo para atender as suas necessidades básicas, como descanso, estudos, família, lazer, sono, o que acaba tornando-se extremamente estressante com o passar do tempo.

Apesar de todos os problemas enfrentados, estes estudantes não desistiram de graduar-se. Por isso é desafiador e estimulante descobrir a razão da persistência destes alunos em perseguir esta meta.

De acordo com Silva ${ }^{(3)}$ a escolha de uma profissão é definida pela ascendência histórica do indivíduo, isto é, ao optar por uma determinada profissão ele sofre influência das experiências que teve ao longo da sua vida, de fatores internos e externos, dos familiares e do mercado de trabalho no qual está inserido. Isto inclui sua capacidade de lidar com frustrações e conflitos, e também seus valores éticos.

Diante destas influências, considero fundamental reconhecer a motivação dos estudantes que cursam Enfermagem, pois para que eles consigam terminar o curso, é necessário que estejam preparados para superar as dificuldades que enfrentarão neste período.

\section{MOTIVAÇÃO}

Alguns definem motivação como estímulo, outros, consideram-na impulso, energia ou, ainda, uma necessidade. Entretanto, a característica mais importante da motivação é que ela faz parte do comportamento do homem, é inerente ao ser humano, ela tem a capacidade de movê-lo e direcioná-lo para alcançar um objetivo.

A motivação está ligada ao comportamento humano, a um processo interno que ocorre em cada indivíduo para satisfazer as suas necessidades e alcançar determinado(s) objetivo(s). Maluf (4) e Nuttin ${ }^{(5)}$ acreditam que a motivação tem como função ativar e direcionar o comportamento para que o indivíduo possa conseguir atingir sua(s) meta(s).

Considerando a motivação sob esta perspectiva, acredito que o técnico e o auxiliar de enfermagem, ao ingressar na graduação, enfrentam dificuldades que surgem durante a sua vida acadêmica e persistem em atingir seu ideal que é, um dia, ser enfermeiro.

\section{A MOTIVAÇÃO NA APRENDIZAGEM}

A motivação exerce influências profundas em nossa vida e envolve todas as condições de comportamento, aprendizagem, desempenho, percepção, atenção, recordação, esquecimento, idéia, criatividade e sentimento ${ }^{(6)}$.

Ao focalizá-la na aprendizagem dos graduandos de enfermagem que já têm experiência, observo que eles encaram esta experiência como um fator propulsor na aprendizagem teórica e prática durante o curso.

Noronha ${ }^{(7)}$ diz que estudar a motivação no trabalho e no ensino de enfermagem é extremamente importante diante das características da profissão, já que esta envolve seres humanos, na figura do enfermeiro, do funcionário, do paciente e do aluno.

A partir do exposto, acho essencial refletir sobre a motivação no processo educativo da enfermagem, pois ela contribui para o crescimento, o desenvolvimento e a formação de 
profissionais capacitados para desempenhar suas funções. Assim, a opção profissional é vista como um processo de crescimento, de exploração de potencialidades, de identificação e aceitação de si próprio, de harmonização ou integração dos motivos individuais e sociais, que acabam refletindo em um trabalho de qualidade.

\section{OBJETIVO}

Apreender os motivos que levam o técnico e o auxiliar de enfermagem a cursar a graduação em Enfermagem.

\section{MÉTODO}

Para desenvolver este tema, optei por uma abordagem qualitativa, pois tenho como foco tentar compreender o universo de significados que envolve as ações e relações humanas, como também a possibilidade de mergulhar na realidade de suas vivências. Como método, utilizei a História Oral que é definida como

\begin{abstract}
um conjunto de procedimentos que se iniciam com a elaboração de um projeto e continuam com a definição de um grupo de pessoas (ou colônia) a serem entrevistadas, com o planejamento da condução das gravações, com a transcrição, com a conferência do depoimento, com a autorização para o uso, arquivamento e, sempre que possível, com a publicação dos resultados... ${ }^{(8)}$.
\end{abstract}

Por tratar-se de um assunto inserido num contexto específico da vida dos auxiliares e técnicos que estão cursando Enfermagem, conduzi o estudo sob a perspectiva da História Oral Temática, que segundo Meihy ${ }^{(8)}$ é a narrativa mais restrita do depoente, mais direcionada a um assunto específico e preestabelecido, na qual ele se compromete a esclarecer, dar a sua opinião ao entrevistador sobre algum evento definido. Esta abordagem da História Oral permite combiná-la com a História Oral de vida, e o que se busca é unir os dados objetivos do depoente às informações obtidas.

Na História Oral o depoente é denominado colaborador porque assume papéis significativos durante todo o processo, desde a etapa do relato, passando pela transcriação e revisão do texto, até a autorização para publicar uma parte ou a entrevista inteira ${ }^{(8)}$.
A base da História Oral é o depoimento gravado, que exige algumas medidas anteriores às gravações: agendar as entrevistas, conforme a conveniência do colaborador; comparecer ao local no horário e data marcados; criar um clima amigável e acolhedor, essenciais à confidência e ao respeito; solicitar consentimento para gravar.

É importante ressaltar que, antes da gravação, é necessário registrar os dados de identificação como: nome do projeto, data, nome do entrevistador e do entrevistado, e o local da gravação. Deve-se informar ao entrevistado que ele poderá conferir a entrevista e que nada será publicado sem a sua permissão.

De acordo com Meihy ${ }^{(8)}$ depois da entrevista será necessário transformar o relato oral em texto escrito para torná-la disponível ao público. Sendo assim, deve-se percorrer as seguintes etapas:

- Transcrição: é a passagem fiel da entrevista da fita para o papel, mantendo os erros de linguagem, ruídos, barulhos, as repetições e incompreensões, incluindo as perguntas do entrevistador;

- Textualização: é a etapa em que as perguntas são suprimidas e agregadas às respostas. O texto passa a ser de domínio exclusivo do colaborador, que assume, como figura única, a primeira pessoa. É preciso que a narrativa seja reorganizada para facilitar a compreensão. Escolhe-se o Tom vital uma frase utilizada na introdução da entrevista que significa a essência da narrativa;

- Transcriação: nesta etapa o texto é recriado de maneira mais ampla. Há inferência do autor no texto, que será refeito várias vezes, mas sempre obedecendo critérios combinados com o colaborador. É importante, neste procedimento, que o colaborador legitime o texto. Terminada esta etapa a versão do texto estará pronta.

\section{Cenário da Pesquisa}

A pesquisa foi feita no Hospital Universitário da Universidade de São Paulo(HU-USP).

\section{Os Colaboradores da Pesquisa}

A escolha dos colaboradores obedeceu a alguns critérios. Eles deveriam:

- Ser auxiliar ou técnico de enfermagem;
A busca da graduação em enfermagem como opção dos técnicos e auxiliares de enfermagem 
- Estar cursando enfermagem;

- Estar trabalhando no HU-USP.

Assim, dirigi-me ao Serviço de Apoio Educacional (SEd) do DE do HU-USP, onde informada sobre quais eram os técnicos e auxiliares de enfermagem que atendiam a esses requisitos.

Em seguida, entrei em contato com as respectivas chefias das unidades para ser apresentada a eles.

A definição dos colaboradores foi feita depois desta apresentação, e os que aceitaram participar do estudo mostaram disponibilidade e interesse. Onze colaboradores dispuseram-se a participar da pesquisa, dos quais oito eram auxiliares de enfermagem e três técnicas de enfermagem.

\section{Procedimentos para a coleta de dados}

Para fazer as entrevistas, marcamos a data, o local e a hora, conforme a disponibilidade de cada um. Expliquei ao colaborador o tema da pesquisa, o objetivo e avisei que a entrevista seria gravada. Antes de começar, pedi que todos assinassem o termo de consentimento pós-informação. Para manter sigilo sobre a verdadeira identidade dos colaboradores, utilizei nomes fictícios, inspirados em títulos de óperas célebres. Esse mesmo sigilo foi adotado também em relação aos nomes das faculdades onde eles estudam, chameias apenas de faculdades privadas.

No início das entrevistas solicitei aos colaboradores que me informassem:

- Seus dados pessoais como: nome completo, idade, estado civil, horário de estudo e trabalho, nome da faculdade, ano letivo, se trabalhava em mais de um emprego, local de trabalho e sua respectiva unidade e ocupação;

- Sua história de vida relacionada à escolha da enfermagem;

- Os motivos da busca pela graduação;

- Disponibilidade de tempo para o estudo, o lazer e o trabalho;

- Desejo em dar continuidade aos estudos.

Ao término de cada entrevista, efetuei as etapas de transcrição, textualização e transcriação.

\section{Procedimentos para análise das entrevistas}

Neste estudo, adotei a modalidade de análise temática porque possibilita apreender opiniões, atitudes, valores e crenças dos indivíduos sobre diversos problemas vivenciados no cotidiano.

Para analisar os dados obtidos nas entrevistas utilizei a técnica de análise de conteúdo proposta por Bardin ${ }^{(9)}$ que considera este método aplicável a qualquer comunicação. Ela define

como um conjunto de técnicas de análise das comunicações visando obter, por procedimento sistemático e objetivo de descrição do conteúdo das mensagens, indicadores que permitem a inferência de conhecimentos relativos às condições de produção/recepção (variáveis inferidas) destas mensagens.

Primeiramente li, diversas vezes, o material transcrito, a fim de me envolver mais com as histórias relatadas. Este procedimento baseia-se na idéia de leitura flutuante, compreendida por Bardin (9) como a leitura necessária para um maior conhecimento do material, que consiste em um deixar-se invadir por impressões e orientações.

Após essas leituras, destacamos as unidades de registros que também segundo Bardin ${ }^{(9)}$ é

$$
\begin{aligned}
& \text { a unidade de significação a codificar e } \\
& \text { corresponde ao seguimento de conteúdo } \\
& \text { a considerar como unidade de base (...). }
\end{aligned}
$$

Destes surgiram os temas e subtemas apreendidos nos depoimentos, tanto pela freqüência com que foram colocados quanto pela força expressiva dos acontecimentos e opiniões mais importantes.

\section{ANÁLISE DOS RESULTADOS}

Neste processo de análise, examinei as histórias contadas pelos graduandos em enfermagem no que se refere aos aspectos:

\section{Os fatores que motivaram a escolha pela enfermagem}

Neste tema, abordei os fatores determinantes que levaram os profissionais de nível médio a decidirem a cursar enfermagem. 
Aida relata que durante a infância gostava de brincar de enfermeira:

Desde criança eu queria ser enfermeira!!! (...) Já tinha aquela idéia formada, vou ser enfermeira! Brincava de boneca como enfermeira.

Martins ${ }^{(10)}$ afirma que o desenvolvimento vocacional advém de um processo contínuo que, a partir das diversas experiências pessoais, escolares e profissionais, proporciona a imersão das potencialidades, dos interesses e das necessidades que permearão a conduta vocacional do indivíduo. Apesar de existirem alguns momentos cruciais, em que o indivíduo precisa fazer uma escolha profissional, como o vestibular ou um processo seletivo para obter emprego, é fundamental repensar essa escolha ao longo da vida, pois a satisfação profissional é extremamente importante.

\section{A influência materna}

A identificação profissional pode ser influenciada pela história do indivíduo, pelas suas experiências na infância com a família, levando-o a refletir sobre a sua escolha profissional.

Constato que algumas das colaboradoras tiveram influência materna, já que as mães trabalhavam na área de enfermagem.

\section{Destaco a fala de Valquíria}

(...) Minha mãe era auxiliar de enfermagem. (...) A enfermagem começou cedo na minha vida (...) Com o passar dos anos, fui crescendo e minha mãe ficava na minha cabeça falando: - 'Você tem que fazer enfermagem!!' Toda minha família vivia falando que eu tinha que fazer enfermagem!

Segundo Bohoslavsky ${ }^{(11)}$ a família é o primeiro grupo de participação e referencial, dada a sua enorme importância na vida de qualquer indivíduo, pois transmite aos filhos seus valores e atitudes, tanto positivos quanto negativos. Desse modo, estes fatores podem exercer um papel relevante e influenciar a escolha de determinada profissão. E certamente tiveram influência na experiência vivenciada por VALQUÍRIA, uma vez que sua mãe induziu sua opção pela graduação em enfermagem.

\section{A enfermeira como modelo}

O enfermeiro desempenha o papel de coordenador de equipe, e quando esta atuação é reconhecida como de alta qualidade, tornase um modelo no qual todos querem se espelhar.

Silva ${ }^{(12)}$ descreve que, muitas vezes, aspectos totalmente subjetivos, e até mesmo indefinidos, decidem o destino profissional das pessoas, que nem sempre percebem o grau de influência no momento em que vivenciam a experiência de escolher uma profissão.

Vários colaboradores disseram que a enfermeira da instituição onde trabalham é o modelo profissional que eles querem seguir. Diz Madame Butterfly:

\begin{abstract}
Nesse tempo que estou estudando e trabalhando no $\mathrm{HU}$, conheci pessoas que foram referências, quanto à atuação como enfermeiras. A que nunca vou esquecer é a enfermeira Ana Maria, que trabalhou aqui (...). Ela atuava da maneira que quando se aprende na faculdade, se coloca na prática... O que me motivou bastante...(...) Eu pretendo ser uma boa enfermeira, quero me espelhar nas enfermeiras do HU... Porque vejo a enfermagem acontecer.
\end{abstract}

\section{A descoberta vocacional}

A vocação está consagrada em um sentido específico, como intimamente ligada à ocupação profissional.

Menezes et al. (13) ao estudar o perfil dos graduandos de enfermagem da Escola Anna Nery nas décadas de 20, 30 e 90, constataram que um dos motivos que levaram estes alunos a procuraram a enfermagem foi a vocação.

Destaco o discurso de Valquíria que expressa com muito sentimento e entusiasmo a sua vocação pela enfermagem.

\footnotetext{
Senti que era tudo que queria!!! A vida inteira, a vida inteira... Essa era a minha verdadeira vocação!!! (...) Eu acho que na enfermagem precisa ter dom. Tudo na vida há necessidade, mas na enfermagem precisa gostar.
}

\section{A motivação para realizar o curso de enfermagem}

O homem, durante toda a sua vida, sempre procurou realizar algo. Dessa forma, estabelece meios para concretizar seus objetivos.
A busca da graduação

em enfermagem como opção dos técnicos e auxiliares de enfermagem 
Neuma Vital Julca Medina Regina Toshie Takahashi

\section{A graduação como meio de crescimento pessoal, profissional e para a busca de conhecimento}

Este tema foi abordado por vários colaboradores. Observo que, para eles, a busca de crescimento pessoal, profissional e de conhecimento constituíram fatores motivadores na decisão de cursar a graduação, como afirma Carmem:

Fazer a graduação em enfermagem significa muito para mim, é realização pessoal, profissional e satisfação do ego. Acredito que tenho capacidade muito maior como enfermeira do que como auxiliar. Fui à procura da melhora da minha qualidade...

A partir do relato de Carmem constato que a graduação em enfermagem foi um dos motivos encontrados para satisfazer o seu ego e também melhorar a sua qualificação profissional.

Schein ${ }^{(14)}$ afirma que o sucesso profissional advém do processo de alcançar ou ultrapassar o nível de aspiração do indivíduo, e este sucesso é influenciado por um conceito admitido pela sociedade.

\section{O papel do enfermeiro}

Para Trevizan et al. ${ }^{(15)}$ o enfermeiro tem como funções específicas o julgamento de situações, a tomada de decisão, a orientação e supervisão de sua equipe de enfermagem, $o$ controle e a avaliação de todas as atividades realizadas em sua unidade, isto é, a administração da unidade visando a assistência integral com qualidade prestada aos pacientes. Destaco a fala de O Messias:

Pensava que chefe era somente o médico. Então hoje sei da função do auxiliar, do técnico, do enfermeiro, da chefia de enfermagem, e que em alguns hospitais existe Diretoria de Enfermagem.

\section{Experiência prévia na enfermagem como elemento facilitador da aprendizagem}

Visualizando a continuidade nos estudos de enfermagem pelos profissionais de nível médio, considero relevante este aspecto, pois salienta a importância de seus conhecimentos técnicos como elemento facilitador durante o processo educativo. Mais uma vez recorro à opnião de O Messias:
Trabalhando como auxiliar de enfermagem, a visão que tenho hoje é bem meIhor, comparando com alguns colegas da faculdade que não trabalham em hospital (...) Mas a gente que trabalha, no meu ver, tem um certo grau melhor, em relação ao conhecimento prático!...

Noronha ${ }^{(16)}$ considera essencial, no ensino de enfermagem, a correlação com o real, isto é, a aquisição dos conhecimentos científicos a partir do desempenho de habilidades práticas.

\section{As dificuldades para conciliar estudo $e$ trabalho}

Atualmente, o número de pessoas que precisam estudar e trabalhar é elevado devido à situação sócio-econômica do mundo capitalista em que vivemos. Assim, aqueles que não têm condições de somente estudar são obrigados a também trabalhar para pagar a escola e ajudar no sustento da família.

\section{Tempo para se dedicar ao estudo}

Apesar das dificuldades encontradas por estes alunos durante a graduação, eles conseguem superar estas barreiras graças à motivação que os impulsionavam. A fala de Fatinitza mostra bem o poder da motivação ao relatar os obstáculos encontrados em sua vida de graduanda.

\footnotetext{
Minha vida tem sido muito corrida, muito corrida mesmo!! Desde que comecei a fazer a graduação e trabalhar também! O tempo que me sobra para estudar é só a noite e acabo virando a madrugada estudando... É estressante (...) Durante as aulas, procuro prestar bastante atenção, é o que me ajuda...(...) No final, se consegue vencer o sofrimento...
}

Em sua pesquisa sobre as condições de estudo do aluno/ trabalhador durante a formação acadêmica em enfermagem, Marra ${ }^{(17)}$ concluiu que a média de horas dedicadas, diariamente, ao estudo extra escolar foi de 30 minutos por aluno. No entanto, a autora não informa qual seria o tempo diário ideal para esta atividade. Ela deduziu, ainda, que esses 30 minutos são destinados a estudar as matérias/disciplinas nas quais o graduando necessita tirar maior nota.

\section{Olazer}

Hoje, o conceito de qualidade de vida envolve vários aspectos que interferem nas relações humanas e, dentre eles, o lazer é bas- 
tante citado como algo fundamental, uma necessidade básica do ser humano.

A dificuldade para desfrutar do lazer foi mencionada por todos os colaboradores. No entanto, ressalto a fala de Valquíria:

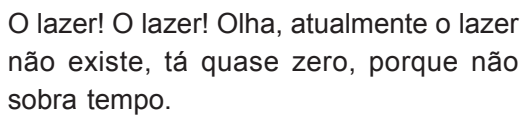

Limongi, Rodrigues ${ }^{(18)}$ referem que viver um cotidiano nem sempre favorável como o desejado, segundo os projetos de vida de cada um, representa um verdadeiro desafio à sobrevivência de seu modo de ser, de pensar e de manter o bem- estar biológico, psicológico e social. Eles afirmam, ainda, que os diferentes fatores e tensões vivenciadas pelo indivíduo, nas suas relações diárias, estão relacionados ao número de atividades desenvolvidas por este indivíduo.

\section{O convívio familiar}

Atualmente, todos nós sabemos que o convívio familiar fica aquém do que gostaríamos, pois o mundo capitalista nos envolve de forma que, por mais que tentemos valorizar essa integração, a cada dia ela se torna mais escassa.

Lunardi ${ }^{(19)}$ salienta que o trabalho aos domingos e feriados impõe restrições à vida familiar e social, devido à dinâmica nas organizações que exigem um trabalho ininterrupto, principalmente na área de saúde.

No cotidiano de Cinderela há uma deficiência no convívio familiar e social durante a graduação, como ela mesma conta.

Tenho que me sacrificar... Quem mais sofre são os filhos. Se não fosse a minha mãe que é maravilhosa e cuida dos meus filhos, eu não conseguiria fazer a faculdade.

\section{As expectativas}

Durante a graduação houve uma identificação do desejo de dar à continuidade à trajetória profissional. Constatei, ainda, que havia nesses indivíduos a motivação para novos empreendimentos de aprimoramento profissional.

\section{Continuar a busca de conhecimentos}

Partindo do pressuposto de que a educação é um processo contínuo que envolve a construção e transformação do conhecimen- to, a Folha-Sinapse ${ }^{(20)}$ afirma que, diante das exigências do mercado de trabalho, quem não se atualizar ou parar de aprender ficará do lado de fora. Por isso, não basta ter somente um diploma, é preciso, sim, manter-se atualizado na profissão que se escolheu.

A busca contínua pelo conhecimento foi destacada por Aida:

Futuramente, se tiver condições físicas e monetárias, se possível, quero fazer o mestrado..

\section{Definição da área de atuação profissional}

A partir das experiências vivenciadas, o indivíduo escolhe a sua área de atuação. No entanto, o amadurecimento desta definição é influenciado pelas inúmeras e diferentes experiências acumuladas durante o percurso do indivíduo como graduando e também como profissional, principalmente quando obtiver um feedback significativo referente a cada um desses percursos.

La Bohème já tem preferência profissional:

$\mathrm{O}$ ano que vem quero fazer especialização na área que mais gosto, em centro cirúrgico. Trabalharei seis horas como enfermeira e o tempo restante farei a especialização... Começar a estudar para valer mesmo!

Schein $^{(14)}$ considera é fundamental que a própria pessoa administre a sua carreira. Porém, caso ela desconheça as necessidades e tendências relativas à profissão, não conseguirá fazê-lo de forma construtiva. Neste sentido, acredito ser essencial para a eficiência e o bom desempenho profissional que a carreira de enfermagem seja seguida por indivíduos comprometidos e conscientes do seu verdadeiro papel, pois só assim será possível atingir a realização, tanto profissional quanto pessoal.

\section{CONSIDERAÇÕES FINAIS}

Os desafios do século XXI exigem cada vez mais dos indivíduos a busca pelo conhecimento. Dentro deste enfoque devo considerar a importância do avanço no campo da enfermagem; porém, este desenvolvimento somente ocorrerá se todos os profissionais se conscientizarem da necessidade de conciliar a dinâmica das atividades na área da assistência, do ensino e da pesquisa.
A busca da graduação em enfermagem como opção dos técnicos e auxiliares de enfermagem 
Neuma Vital Julca Medina Regina Toshie Takahashi
Ao interiorizar os dados coletados, percebi que os meus colaboradores têm um grande desejo de ser enfermeiros. Notei, muitas vezes, que seus relatos estavam permeadas de experiências e perspectivas, fontes de motivação para eles enfrentarem os obstáculos durante a graduação e superar qualquer barreira que possa atrapalhar o alcance do objetivo.

Acredito que a motivação tenha uma enorme capacidade de atuar sobre estes graduandos, incentivando-os a procurar satisfazer o seu desejo profissional.

Diante disto, considero fundamental que os educadores procurem estratégias que facilitem facilitar a participação destes graduandos em sua formação acadêmica, respeitando o conhecimento que eles têm da profissão, resultado da prática diária. Assim será possível alcançar uma formação com qualidade.

\section{REFERÊNCIAS}

(1) Zanei SSV. Mobilidade sócio-profissional na enfermagem: aspectos de uma realidade em reconhecimento. Acta Paul Enferm 1995; 8(4):19-27.

(2) Zanei SSV. Mobilidade ocupacional: as representações deste processo na enfermagem. [dissertação] São Paulo (SP): Escola de Enfermagem da USP; 1998.

(3) Silva LBC. A escolha da profissão uma abordagem psicossocial. São Paulo: Unimarco; 1996.

(4) Maluf MR. A motivação, a criança, a formação profissional. [livre-docência] São Paulo (SP): Instituto de Psicologia da USP; 1994.

(5) Nuttin J. Teoria da motivação humana: da necessidade ao projeto de ação. São Paulo: Loyola; 1983.

(6) Murray EJ. Motivação e emoção. Trad. de Álvaro Cabral. $3^{\text {a }}$ ed. Rio de Janeiro: Zahar; 1983.

(7) Noronha R. Motivação no ensino e na assistência de enfermagem. Rev Bras Enferm 1985; 38(1): 70-5.

(8) Meihy JCSB. Manual de história oral. São Paulo: Loyola; 2000.

(9) Bardin L. Análise de conteúdo. Trad. de Luis Antero Reto e Augusto Pinheiro. Lisboa: Edições 70; 1979.

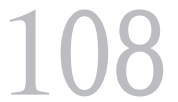

Rev Esc Enferm USP 2003; 37(4): 101-8.
(12) Silva MLR. Personalidade e escolha profissional- subsídios de Keirsey e Bates para a orientação vocacional: São Paulo: EPU; 1992.

(13) Menezes SS, Baptista SS, Barreira IA. O perfil das(os) alunas(os) de enfermagem da Escola Anna Nery: décadas de 20,30 e 90. Esc Anna Nery Rev Enferm 1998; 2(1/2): 35-48.

(14) Schein EH. Identidade profissional: como ajustar suas inclinações e suas opções de trabalho. São Paulo: Nobel; 1996.

(15) Trevizan MA, Mendes IAC, Fávero N. Subutilização do preparo profissional do enfermeiro. Rev Gaúcha Enferm 1984; 5(1): 101-11.

(16) Marra CM. Condições de estudo do aluno/ trabalhador durante a formação acadêmica em enfermagem. [dissertação] São Paulo (SP): Escola Paulista de Medicina da UNIFESP; 1996.

(17) Limongi AC, Rodrigues AL. Como gerenciar sua saúde no trabalho: um manual sobre estresse e queixas psicossomáticas no dia a dia nas empresas. São Paulo: Editora STS; 1994.

(18) Lunardi DWF. Prazer e sofrimento no trabalho: contribuições à organização do processo de trabalho da enfermagem. Rev Bras Enferm 1997; 50(1): 77-92.

(19) Lunardi DWF. Prazer e sofrimento no trabalho: contribuições à organização do processo de trabalho da enfermagem. Rev Bras Enferm 1997; 50(1): 77-92.

(20) Ensino Superior. Folha de São Paulo [periódico online] São Paulo; 2002 julho 23. Disponível em: $\leq$ http://www.folha.com.br/sinapse $>$ (23 jul. 2002) 